\title{
Results of a prospective algorithm to remove chest tubes after pulmonary resection with high output
}

\author{
Robert James Cerfolio, MD, FACS, FCCP, and Ayesha S. Bryant, MSPH, MD
}

From the Section of Thoracic Surgery, Division of Cardiothoracic Surgery, Department of Surgery ${ }^{\mathrm{a}}$ and the Division of Cardiothoracic Surgery, Department of Epidemiology, School of Public Health, ${ }^{\text {b }}$ University of Alabama at Birmingham, Birmingham, Ala.

Presented at the Thirty-third Annual Meeting of the Western Thoracic Surgical Association, Santa Ana Pueblo, NM, June 27-30, 2007.

Received for publication June 25, 2007; revisions received Aug 7, 2007; accepted for publication Aug 17, 2007.

Address correspondence to: Robert J. Cerfolio, MD, Professor of Surgery, Chief of Section of Thoracic Surgery, Division of Cardiothoracic Surgery, University of Alabama at Birmingham, $70319^{\text {th }}$ St S, ZRB 739, Birmingham, AL 35294 (E-mail: rcerfolio@uab.edu).

J Thorac Cardiovasc Surg 2008;135:269-73 $0022-5223 / \$ 34.00$

Copyright $(2008$ by The American Association for Thoracic Surgery

doi:10.1016/j.jtcvs.2007.08.066
Objective: Many patients have their hospital discharge delayed because their chest tube drainage is too high, despite the fact that there are no data to support the commonly used $250 \mathrm{~mL} /$ day threshold.

Methods: A retrospective cohort study was conducted with a prospective database and prospective algorithm from one surgeon. All patients underwent elective pulmonary resection. The last chest tube was removed if there was no air leak and nonchylous drainage of $450 \mathrm{~mL} /$ day or less.

Results: The study comprised 8608 operations and 2077 patients who underwent an elective (nonpneumonectomy) pulmonary resection via thoracotomy by one general thoracic surgeon over a 10-year period. Eighty-nine patients went home with a chest tube owing to air leak. The remaining 1988 patients were discharged without a chest tube. Types of pulmonary resection were wedge resection in 729 patients, segmentectomy in 214 , lobectomy in 1104 , and bilobectomy in 30 . The median day of discharge was postoperative day 4 . One hundred one $(5 \%)$ were readmitted to the hospital within 60 days of discharge. The most common reason for readmission was dehydration and fatigue. Only $11(0.55 \%)$ had readmissions owing to recurrent symptomatic effusion and most were treated with video-assisted thoracoscopy. Follow-up was $100 \%$ at 4 weeks and $93 \%$ at 8 weeks.

Conclusions: Chest tubes can be removed with up to $450 \mathrm{~mL} /$ day of nonchylous drainage after pulmonary resection, and perhaps a higher volume could be accepted. Readmission owing to a recurrent effusion is exceedingly uncommon, and the practice of leaving the tube in longer for drainage less than $450 \mathrm{~mL} /$ day is unsupported in the literature.

$\mathrm{C}$ hest tubes and the pleural space are and should remain a well-protected bastion of thoracic surgery. However, surgeons apply different rules for chest tube management. These vagaries in management erode the confidence our medical colleagues have in our decision-making skills concerning these tubes. One reason for the variations in management centers is the lack of data that support one practice technique over another. Specifically, despite the large amount of recent prospective data on chest tube management owing to air leaks, ${ }^{1-4} *$ there has been a paucity of literature concerning the optimal time to remove a chest tube after pulmonary resection on the basis of the amount of pleural drainage. Patient discharge is frequently delayed because the last chest tube is not removed since the drainage is "too high" to allow safe removal. The objective of this study was to assess the outcomes of a prospective algorithm that was applied to a series of patients who underwent elective pulmonary resection and who had their last chest tube removed when the nonchylous effluent was $450 \mathrm{~mL} /$ day or less.

* Cerfolio RJ, Bass CS, Pask AH. A prospective randomized trial: is water seal safe for everyone? Unpublished data. 


\section{Abbreviation and Acronym}

$\mathrm{POD}=$ postoperative day

\section{Materials and Methods \\ Patients}

In this series, we applied a prospective algorithm to all patients between January 1997 and December 2006 who underwent pulmonary resection by one general thoracic surgeon at the University of Alabama at Birmingham. Only patients who underwent elective thoracotomy and nonpneumonectomy pulmonary resection were eligible for this study. Patients were excluded if they were less than 19 years of age, discharged home with their chest tubes still in place, or underwent decortication, empyectomy, pneumonectomy, video-assisted thoracoscopic pulmonary resection, or esophagogastrectomy. Patients with non-small cell lung cancer who underwent pulmonary resection had complete thoracic lymphadenectomy as previously described. ${ }^{5}$ The University of Alabama at Birmingham's Institutional Review Board approved the study and the electronic prospective database used for this study. Patient consent was obtained for entry into the prospective database and patients were aware that this information would be used for research purposes. Outcomes included hospital length of stay, the amount of chest tube drainage (milliliters) for each postoperative day (POD), morbidity, 60-day readmission, and cause(s) of readmissions.

Follow-up data were obtained from hospital and clinic databases as well as our office prospective database, in which any postdischarge patient-related calls are logged by our clinical team. Over half of the study patient population was seen and evaluated in our postoperative clinic. Two-month follow-up in the form of telephone calls, clinic visit records, physician updates, and/or outside databases such as the Social Security Death Index was accomplished in $93 \%$ of the patients in this study.

\section{Chest Tube Management}

From January 1997 until December 2004, most patients had two chest tubes placed. One was positioned apically and posteriorly and the other apically and anteriorly after lobectomy. After January 2005 , only one apically and posteriorly placed chest tube was used after lobectomy. One tube was used for wedge resection or segmentectomy throughout the study time frame. However, if patients had an air leak that could not be sewn closed before chest closure and there appeared to be a space problem after lung expansion, a second chest tube was placed apically and anteriorly. All chest tubes were No. 28F soft Deknatel (Teleflex, Mansfield, Mass) tubes. They were connected to a Sahara S-1100a Pleur-evac Chest Drainage System (Genzyme Biosurgery, Cambridge Mass). Tubes were put on $-20 \mathrm{~cm}$ of wall suction on the day of surgery and then were changed to water seal on the morning of POD 1. Tubes remained on water seal unless symptomatic pneumothorax and/or subcutaneous emphysema developed. ${ }^{6}$

The amount of chest tube drainage was recorded every 12 hours (in milliliters) by the nursing staff. In addition, the level of the drainage was further verified by the resident and/or cardiothoracic fellow during rounds by placing a mark on the level of drainage each morn- ing on rounds. Both the drainage amount and its appearance were recorded each day. The last chest tube was removed when the effluent was nonchylous in character (not milky), less than $450 \mathrm{~mL} / \mathrm{day}$, and there was no air leak. In general, patients were sent home the day the last chest tube was removed. If the drainage appeared white or milky it was sent for triglyceride content analysis and the patient was asked to eat a fatty meal. A triglyceride level of $110 \mathrm{mg} / \mathrm{dL}$ or greater ${ }^{7}$ was considered diagnostic of a chylothorax and tubes were not removed.

\section{Definitions}

High-output chest tube drainage was defined as drainage greater than $250 \mathrm{~mL}$ per 24 hour period. The readmission rate was defined as any readmission within 2 months of the date of discharge and was determined by the use of multiple databases. For patients who were readmitted to other services at the University of Alabama at Birmingham or to other hospitals, the cause for readmission and the treatment rendered were determined by review of our notes, letters and notes from the admitting physician, and by the discharge summary. Patients who were readmitted to our hospital but placed on another service were seen by us as well. A readmission that was due or partially due to a pleural effusion was defined as readmission within 60 days of discharge of any patient (1)whose pleural effusion was determined to be the cause of the readmission, (2) whose symptoms that led to the readmission were possibly due to the pleural effusion, (3) whose pleural effusion was greater on readmission than on discharge, and (4) who required any type of intervention to drain an effusion that was ipsilateral to the previous thoracotomy performed within the preceding 60 days. Continuous data are presented as means and categorical data are presented as percentages. The Fisher exact test or Pearson $\chi^{2}$ test was used to assess categorical data and the Wilcoxon test to evaluate continuous variables.

\section{Results}

Between January 1997 and December 2006, 8608 operations were performed under general anesthesia by one general thoracic surgeon; however, only 2077 patients underwent an elective (nonpneumonectomy) pulmonary resection via thoracotomy. The median age was 67 years (range $20-89$ years). Eighty-nine patients went home with a chest tube because of air leak. The remaining 1988 patients were discharged without a chest tube and were the denominator used for the calculation of readmission rates for this study. Figure 1 depicts the average amount of chest tube drainage on PODs 1 through 4 . The types of pulmonary resection performed were wedge resection in 729 patients, segmentectomy in 214 , lobectomy in 1104 , and bilobectomy in 30 . The median day of discharge was POD 4. Figure 2 shows the average amount of chest tube drainage based on the type of pulmonary resection performed. It shows that the volume decreased each POD and lobectomy was associated with the highest amount of drainage. Table 1 depicts the number of patients who were discharged on each POD. In addition, it shows how many patients were sent home with a chest tube drainage between 250 and $450 \mathrm{~mL} /$ day. For example, on the second POD, 83 patients (4\% of the 1988) were discharged home and 16 


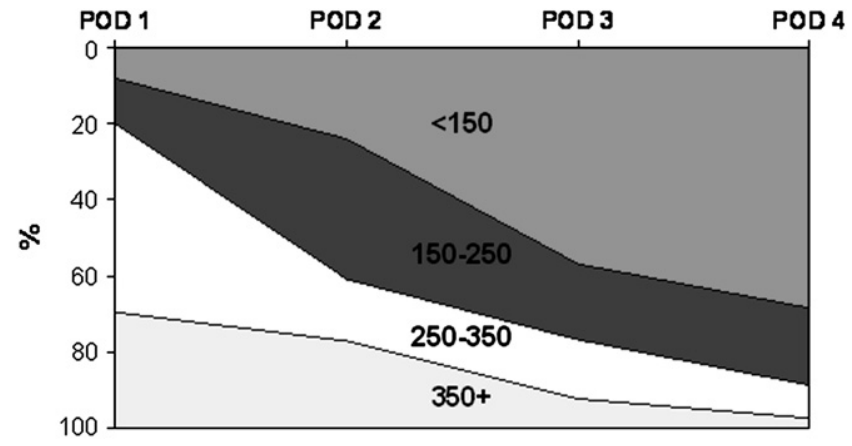

Figure 1. Proportion of patients with varying amounts of chest tube drainage (in milliliters per day) based on each postoperative day (POD).

(19\%) of them had chest tube drainage between 250 and 450 $\mathrm{mL} /$ day. None of these patients were readmitted within 60 days. A total of 364 patients went home with a chest tube output of 250 to $450 \mathrm{~mL} /$ day. Thus $18 \%$ of the 1988 patients in this series were able to go home sooner when the $450 \mathrm{~mL} /$ day threshold was used. In addition, there was no difference in the readmission rate between patients sent home with high output drainage compared with those with low chest tube outputs.

One hundred one (5\%) of patients were readmitted to any hospital within 60 days of discharge. The most common reasons for readmission were dehydration and fatigue. Patients who were discharged early (on POD 2 or 3 ) did not have a higher rate of readmission. Eleven $(0.55 \%)$ patients had readmissions as a result of recurrent symptomatic effusion. Their characteristics are shown in Table 2. As shown, most were treated with video-assisted thoracic surgery. Followup was complete in $100 \%$ of the patient population at 4 weeks and in $93 \%$ of the patient population at 8 weeks.

\section{Discussion}

Thoracic surgeons may make more clinical decisions each day about the management of patients' chest tubes than on any other clinical problem. Often these decisions are made on the basis of biases and preferences learned during training as opposed to evidence-based medicine. This may be attributed to the lack of clinical trials that address "mundane issues" such as chest tube management. For these reasons we have performed several prospective studies and written several chapters ${ }^{8-11}$ on the management of chest tubes. However, these studies have focused primarily on the management of tubes in patients with air leaks. This study focuses on a different issue of chest tube management: the volume of drainage.

A majority of thoracic surgeons prefer to leave chest tubes in until the air leak has resolved and the output is less than $250 \mathrm{~mL} /$ day, ${ }^{12}$ and some even use $200 \mathrm{~mL} /$ day. ${ }^{13}$ In a recent poll at a national meeting of general thoracic surgeons, ap-

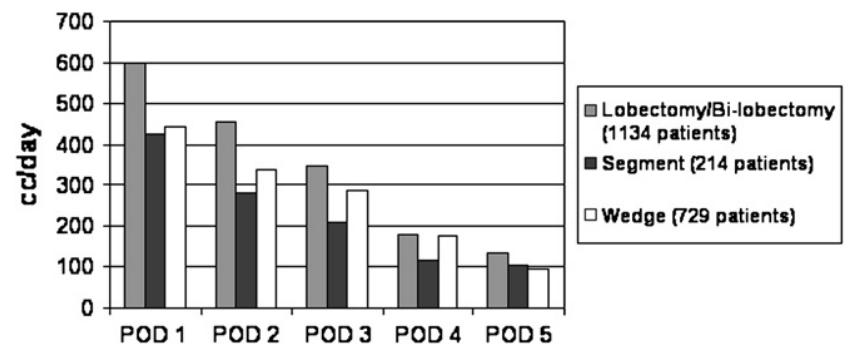

Figure 2. Average chest tube output by procedure for each postoperative day (POD).

proximately $75 \%$ stated that they use $250 \mathrm{~mL} /$ day as their cutoff value for the removal of chest tubes after lung resection. They also stated that high chest tube output was the main reason that delayed discharge and not the presence of air leaks. Thus patient length of stay is often prolonged owing to "the drainage being too high." Despite the fact that the patient is otherwise ready for discharge, the volume of drainage prevents it even though there is little published information to support leaving the patient's tube in. As seen in this series (see Table 1), 16 (19\%) patients were able to go home early on POD 2, 199 (30\%) on POD 3, and $125(15 \%)$ on POD 4 when the threshold of $450 \mathrm{~mL} /$ day was used instead of 250 $\mathrm{mL} /$ day. A total of 364 patients (or 18\%) of the 1988 patients in this series were sent home without a chest tube and thus enjoyed an early hospital discharge. As shown in Table 1, only 19 of them $(19 / 364=5 \%)$ were readmitted. This is a similar readmission rate for the entire patient population, and thus the removal of tubes in patients with a high output does not seem to increase the readmission rate. This provides more evidence that the removal of chest tubes with drainage greater than $250 \mathrm{~mL}$ /day but less than $450 \mathrm{~mL} /$ day is safe. However, we did find that patients who spent more time in the hospital were more likely to be readmitted. Perhaps an even higher threshold for the amount of chest tube drainage may be used, but we have no data to support that practice.

In this study, a prospective algorithm was applied to a consecutive series of patients who underwent elective pulmonary resection. We found that the removal of tubes, even when the effluent was as high as $450 \mathrm{~mL} /$ day, was safe. We included in this study only patients who underwent elective pulmonary resection and eliminated patients who may have had a wedge resection as a secondary part of a more major procedure (ie, decortication, empyectomy, the removal of a mediastinal mass, primary chest wall tumors, Ivor Lewis esophagogastrectomy). However, we did include patients who underwent metastasectomy (had pathologic conditions other than nonsmall cell lung cancer) because we often perform a thoracic lymphadenectomy in these patients as well. We included these patients to make the study applicable to as many patients as possible but yet eliminated other types of procedures 
TABLE 1. The number of patients who had their chest tubes removed with a volume greater than $250 \mathrm{~mL} / \mathrm{day}$ by POD

\begin{tabular}{|c|c|c|c|c|c|}
\hline & \multicolumn{5}{|c|}{ POD last chest tube was removed } \\
\hline & POD 2 & POD 3 & POD 4 & POD 5 & POD $\geq 6$ \\
\hline $\begin{array}{l}\text { No. }(\%) \text { of patients who had their last chest } \\
\text { tube removed on this POD and went home }\end{array}$ & $83(4 \%)$ & $664(32 \%)$ & $830(40 \%)$ & $374(18 \%)$ & $104(5 \%)$ \\
\hline No. $(\%)$ of patients with drainage $>250 \mathrm{~mL} /$ day & $16(19 \%)$ & $199(30 \%)$ & $125(15 \%)$ & $20(5 \%)$ & $4(4 \%)$ \\
\hline $\begin{array}{l}\text { No. }(\%) \text { of patients readmitted for any cause } \\
\text { who had drainage }>250 \mathrm{~mL} / \text { day on } \\
\text { discharge }\end{array}$ & $0(0 \%)$ & $8(4 \%)$ & $8(6 \%)$ & $2(10 \%)$ & $1(25 \%)$ \\
\hline
\end{tabular}

$P O D$, Postoperative day.

to keep the population homogeneous so as to make the conclusions more valid. We found no difference in the readmission rates in patients with high outputs based on the type of pulmonary resection performed.

When a patient has a chest tube output that is greater than $250 \mathrm{~mL} /$ day, other causes for a high output should be eliminated before chest tube removal. The character of the drainage should also be evaluated. If it is milky (suggestive of a chythorax in a patient who is eating), it should be diagnosed and treated. If it is bloody, appropriate treatment should be undertaken. Besides a chylothorax or a hemothorax, a third much less common cause of an unexplained high chest tube output should be considered. Although this complication is very uncommon, it needs to be considered in any patient with a high unexplained output. This third cause is a cerebral-arachnoid pleural fistula. Cerebral-arachnoid pleural fistula is usually associated with a high output and often patients have symptoms of headache, nausea, and confusion. ${ }^{14}$ When these three possibilities are eliminated (which usually only requires clinical acumen and inspection of the effluent's characterization), a serosanguineous effusion that is $450 \mathrm{~mL} /$ day or less is not an indication to leave the chest tube in. It is safe to remove the tube and discharge the patient. Removal of a chest tube in this setting may be safe because the pleural surface is inflamed in the postoperative period and therefore more absorptive. However, the physiologic conditions that explain the absorptive properties are not fully explained.

There are several limitations to this study. First, 2-month follow-up was complete in only $93 \%$ of the patient population. We chose to include the other $7 \%$ because we had their chest tube drainage information and had follow-up data in all of them for at least 4 weeks postoperatively and none had been readmitted at that point. Second, our reported readmission rates for recurrent effusions may be incorrectly low owing to the lack of complete understanding of the hospital course for patients who were readmitted at outside hospital facilities. This may not be negligible because, as is true of many tertiary centers, many of the patients on whom we operate travel significant distance and are often readmitted at outside institutions. Third, we may have underestimated the effusion as the true cause of other readmissions. Fourth, and finally, we may have missed thoracenteses that were performed as an outpatient despite the fact that we had many of the home physicians' clinic records.

TABLE 2. Characteristics of the 11 patients who were readmitted for a symptomatic effusion during the 60-day follow-up

\begin{tabular}{|c|c|c|c|c|c|}
\hline Patient No. & Initial procedure & $\begin{array}{c}\text { Amount of drainage on day of } \\
\text { discharge }(\mathrm{mL} / \text { day })\end{array}$ & $\begin{array}{c}\text { POD of last } \\
\text { chest tube removal }\end{array}$ & $\begin{array}{l}\text { POD of } \\
\text { readmission }\end{array}$ & Treatment on readmission \\
\hline 1 & Lobectomy & 120 & 3 & 8 & VATS \\
\hline 2 & Segmentectomy & 205 & 4 & 9 & VATS \\
\hline 3 & Lobectomy & 175 & 4 & 12 & Thoracentesis \\
\hline 4 & Lobectomy & 240 & 5 & 9 & Redo thoracotomy* \\
\hline 5 & Lobectomy & 285 & 5 & 10 & Observation only \\
\hline 6 & Lobectomy & 85 & 3 & 16 & VATS \\
\hline 7 & Lobectomy & 310 & 4 & 31 & VATS \\
\hline 8 & Lobectomy & 285 & 5 & 20 & $\begin{array}{l}\text { Redo thoracotomy, } \\
\text { empyectomy }\end{array}$ \\
\hline 9 & Lobectomy & 155 & 6 & 24 & VATS, pericardial window \\
\hline 10 & Lobectomy & 130 & 4 & 42 & VATS \\
\hline 11 & Lobectomy & 115 & 5 & 29 & $\begin{array}{l}\text { Redo thoracotomy, } \\
\text { empyectomy }\end{array}$ \\
\hline
\end{tabular}

VATS, Video-assisted thoracoscopic surgery; $P O D$, postoperative day. *Patient with chylothorax. Required redo thoracotomy with duct ligation and pleurectomy. 
In 2001, we ${ }^{15}$ reported our experience with a fast-tracking protocol that was applied to 500 patients who underwent pulmonary resection. In that manuscript we reported a 2- week readmission rate of only $1.8 \%$ despite using a similar protocol for tube removal and discharge. In this report the rate is significantly higher at $5 \%$. This higher rate probably is attributable to the longer follow-up period in this series (60 days compared with 14 days). However, the most common causes for readmission (weakness, fatigue, dehydration, nausea, and/or shortness of breath) are similar in both series.

Patients who are readmitted after thoracotomy and pulmonary resection almost always get a chest radiograph, and many are told they have "pneumonia." The chest radiograph often shows a concomitant small pleural effusion. These radiologic changes are common and expected after thoracotomy with pulmonary resection. These expected postthoracotomy changes are often overinterpreted by nonsurgical physicians. A computed tomographic scan even further leads to nonsurgeons overinterpreting these changes as pathologic instead of the normal healing process. When we are consulted on these patients and the atelectasis is only segmental and the effusion is small, we often suggest that the best treatment is chest physiotherapy and ambulation. If the shortness of breath continues despite conservative management and a chest tomographic ultrasound or radiograph confirms a significant fluid collection, then an ultrasound-guided thoracentesis should be performed to evaluate whether draining any of the fluid actually alleviates symptoms. This is our standard practice when faced with these readmitted patients after thoracotomy. This practice may also have resulted in an underestimation of the incidence of symptomatic effusion in this series.

In conclusion, we have shown that a chest tube can be removed with nonchylous drainage as high as $450 \mathrm{~mL} /$ day after pulmonary resection and perhaps a higher volume could be accepted. Readmission owing to a recurrent effusion is exceedingly uncommon. The practice of leaving the chest tube in place longer because of drainage that is less than $450 \mathrm{~mL} /$ day is unsupported in the literature. Further studies are needed to test a higher volume and to ascertain the causes of readmission after pulmonary resection. Such studies are underway at our institution.

\section{References}

1. Cerfolio RJ, Bass CS, Katholi CR. Prospective randomized trial compares suction versus water seal for air leaks. Ann Thorac Surg. 2001; 71:1613-7.

2. Cerfolio RJ, Tummala RP, Holman WL, Zorn GL, Kirklin JK, McGiffin DC, et al. A prospective algorithm for the management of air leaks after pulmonary resection. Ann Thorac Surg. 1998;66:1726-31.

3. Brunelli A, Fianchini A. Prolonged air leak following upper lobectomy: in search of the key. Chest. 1999;116:848.

4. Brunelli A, Monteverde M, Borri A, Salati M, Marasco RD, Fianchini A. Predictors of prolonged air leak after pulmonary lobectomy. Ann Thorac Surg. 2004;77:1205-10.

5. Cerfolio RJ, Bryant AS. The distribution and likelihood of lymph node metastasis based on the lobar location of non-small cell lung cancer. Ann Thorac Surg. 2006;81:1969-73.

6. Cerfolio RJ. Recent advances in the treatment of air leaks. Curr Opin Pulm Med. 2005;11:319-23.

7. Miller JI Jr. Anatomy of the thoracic duct and chylothorax. In: Shields TW, LoCicero J III, Ponn RB, editors. Genera thoracic surgery. 5th ed. Baltimore: Williams and Wilkins; 2000. p. 509-17.

8. Cerfolio RJ. Advances in thoracostomy tube management. Surg Clin North Am. 2002;82:833-48.

9. Cerfolio RJ. Recent advances in the treatment of air leaks. Curr Opin Pulm Med. 2005;11:319-23.

10. Cerfolio RJ. Chest tube management after pulmonary resection. Chest Surg Clin N Am. 2002;12:507-27.

11. Loran DB, Woodside KJ, Cerfolio RJ, Zwischenberger JB. Predictors of alveolar air leaks. Chest Surg Clin N Am. 2002;12:477-88.

12. Sadovsky R. When to remove a chest tube? A randomized study with subsequent prospective consecutive validation. J Am Coll Surg. 2002; 195:658-62.

13. Baumann MH. What size chest tube? What drainage system is ideal? And other chest tube management questions. Curr Opin Pulm Med. 2003;9:276-81.

14. Lloyd C, Sahn S. Subarachnoid pleura fistula due to penetrating trauma: A case report and review of the literature. Chest. 2002;122:2252-6.

15. Cerfolio RJ, Pickens A, Bass C, Katholi C. Fast-tracking pulmonary resections. J Thorac Cardiovasc Surg. 2001;122:318-24. 